\title{
Power and Control as a Framework for Practice-The Case of Intimate Partner Violence Work in Taiwan
}

\author{
Chu-Li Julie Liu and Cheryl Regehr \\ Version Published Version/Final PDF \\ Citation Liu, C. J., \& Regehr, C. (2009). Power and Control as a Framework for \\ (published version) Practice--The Case of Intimate Partner Violence Work in Taiwan. Brief \\ Treatment and Crisis Intervention, 8(4), 381-389. doi:10.1093/brief- \\ treatment/mhn025
}

Copyright CC BY-NC-ND

\section{How to cite TSpace items}

Always cite the published version, so the author(s) will receive recognition through services that track citation counts, e.g. Scopus. If you need to cite the page number of the author manuscript from TSpace because you cannot access the published version, then cite the TSpace version in addition to the published version using the permanent URI (handle) found on the record page.

This article was made openly accessible by $U$ of $T$ Faculty. Please tell us how this access benefits you. Your story matters. 


\title{
Power and Control as a Framework for Practice-The Case of Intimate Partner Violence Work in Taiwan
}

\author{
Chu-Li Julie Liu, PhD \\ Cheryl Regehr, PhD
}

This qualitative study investigated the views of Taiwanese domestic violence workers regarding the applicability of Western feminist models of intervention in their work with battered women. The findings suggested that workers experienced discrepancies between their training in Western domestic violence practices and their work with Taiwanese women whose beliefs and culture were embedded with Confucian ideology. This study also found that workers had developed alternative strategies that they believed to be useful in working with these women. Implications for incorporating cultural knowledge into practice related to intimate partner violence are addressed. [Brief Treatment and Crisis Intervention 8:381-389 (2009)]

KEY WORDS: intimate partner violence, social workers, Taiwan, confucian culture, qualitative research.

Feminist theory is undoubtedly the most widely adopted theoretical perspective in the field of intimate partner violence. From this standpoint, the socially ascribed power afforded to women and control inherent in men's roles are dominant lenses for analyzing violent relationships. Stemming from this analysis, intervention often focuses on assisting women to identify issues of power and control and educating women about their rights to safety, security, and well-being. Through the processes of

From the Department of Social Work, Tunghai University, Taichung, Taiwan (Julie Liu) and the Factor-Inwentash

Faculty of Social Work, Sandra Rotman Chair, University of

Toronto. E-mail: cheryl.regehr@utoronto.ca.

Contact author: Chu-Li Julie Liu, Associate Professor, Tunghai University, Department of Social Work, 181

Taichung-Kang Road. Section 3, Taichung, Taiwan 330.

E-mail: chuli@thu.edu.tw.

doi:10.1093/brief-treatment/mhn025

Advance Access publication on January 29, 2009 exploration, education, and consciousness raising, women become empowered to make decisions and take actions that are in their own best interest and maximize their potential. Until recently, it has been strongly suggested that this feminist perspective should be a central component of social work education in order to prepare students to address intimate partner violence problems (Danis, 2003).

There is a long history of critiques of the pioneering approaches to feminism, suggesting that women of color were excluded and their unique experiences embedded in their culture were not examined (Jaimes* Guerrero, 2003). Hooks (1981) in her groundbreaking book "Ain't I Woman" a title based on the speech of Sojouner Truth in 1851, argued that the feminist movement was largely aimed at the white middle class and not only ignored the unique

(c) The Author 2009. Published by Oxford University Press. All rights reserved. For permissions, please e-mail: journals.permissions@oxfordjournals.org. 
needs of Black women but also reinforced racism, classism, and sexism. Similar views were expressed by Collins (1990), Davis (1981), and others, causing feminism to reconsider the basic premises and move beyond simply a genderbased analysis. The emergence of womanism, which focused on the multiple oppressions of women of color, expanded the understanding of power and control issues in nonwhite cultures (Hudson-Weems, 2001). Nevertheless, the notion of Womanism was limited to black women in North America, and to a great extent, the experiences of women in other cultures and with other lived experiences continued to be ignored.

Researchers and theorists continue to suggest that feminist theory needs to move further in incorporating unique cultural perspectives (Evan, Kincade, Marbley, \& Seem et al., 2005). To date, however, culturally imbedded views regarding inequality and the relative power held by men and women in non-Western cultures have remained undocumented. Yet ethnocentric explanations of the causes of intimate partner violence that focus on issues of power and control and interventions that emanate from these explanations do not necessarily fit all cultures (Crichton-Hill, 2001). Thus, there is a need for continuing efforts to explore the issue of intimate partner violence and services that can best address the needs of victims, especially in non-Western cultures.

\section{Response to Domestic Violence and Practice Concerns in Taiwan}

In recognition of the problem of violence against women, the Domestic Violence and Sexual Assault Act was enacted by the Taiwanese legislature in 1998. This legislation in some ways follows child abuse reporting laws in other parts of the world and mandates assessment and intervention in cases of woman abuse.
The following year services aimed at the protection of women and mediation of the effects of intimate partner were first launched (Domestic Violence and Sexual Assault Prevention Committee, Ministry of Interior, 2008). These services encompass two different types of structures both of which employ domestic violence workers. Domestic violence and sexual assault centers are under the auspices of the Department of Social Affairs of City Government with a mandate to help battered women and their children in the time of crisis. Additionally, there is a network of "contracted out" social service agencies that are charged with the responsibility of assisting battered women in rebuilding their lives after crisis. Cases of intimate partner violence are first reported to the domestic violence and sexual assault centers within the Department of Social Affairs of the City Government either by frontline social workers in other agencies, for example, social workers in health settings, or by police officers. Upon receiving the report, social workers who work for the City Government are required to visit battered women and collect data within $72 \mathrm{hr}$, file the case before the court, and ensure the safety of the victim. For example, battered women and their children are assisted to relocate to a women's shelter if social workers assess that they continue to be subject to threatening/unsafe situations. Social workers also assist women to obtain protection orders through the courts. Once free of immediate danger, battered women are referred to contracted out social service agencies for further services. These social workers help battered women develop plans for their new lives and provide them with relevant resources.

Social work practice with battered women in Taiwan is similar in many ways to the practice adopted in North America. For instance, the training and practice model are based on Western literature concerning power and control in the husband-wife relationships, the Duluth power and control wheel model (Dominelli, 2002), and a social work strengths perspective. 
However, the cultural framework in which these services are offered varies considerably from that in North America. Taiwanese cultural beliefs, predominantly embedded with Confucian ideology, that influence work with abused women include views regarding male privilege and female submission (Lim, 1997); beliefs about women's responsibility for their own abuse (Tang \& Cheung, 1997; Tang, Wong, \& Cheung, 2002); the importance of honoring family and the primacy of family relationships, including those with the extended and natal family (Yoshihama, 2005); and barriers to disclose negative feelings and events in public (Almeida \& Doland-Delvecchio, 1999; Cousineau \& Rondeau, 2004; Preisser, 1999). All these beliefs lead to a culture of concealment of abuse and victim-blaming attitudes (Chen, 2003; Preisser, 1999; Tsang \& Sung, 2005). Also these cultural beliefs are contradictory to that of feminism.

Since the cultural framework varies from that in North American, a question arises, does the Western social work practice model with battered women fit practice with Taiwanese battered women? This study seeks to explore the experiences and issues that have emerged in domestic violence service work in Taiwan and to explore the application of Western feminist-based models of woman abuse in a culture where egalitarian relationships between men and women have not traditionally existed. In addition, most cross-cultural studies on intimate partner violence are largely based on populations residing in North America. Thus, the victims' experiences are intertwined with the issues of acculturation and assimilation into North American culture and their relations with service providers who do not share the same cultural background with their clients. However, this study focused on experiences of social workers working with victims who shared the same sociocultural backgrounds. In this paper, we report from a qualitative research project with domestic violence social workers in
Taiwan. The study adopted a discovery-oriented qualitative design, to investigate the perspectives of Taiwan's domestic violence service workers regarding the application of feminist perspectives in their work with battered women.

\section{Methodology}

Given the exploratory nature of research questions, a qualitative research method was adopted in this study. Research procedures followed the paradigms of grounded theory approach.

\section{Recruitment}

Letters of introduction that included an explanation of the study, requirements of selecting participants, and an interview guideline containing examples of interview questions were mailed to Domestic Violence Service Centers as well as other "contract out" social service agencies in Taiwan to seek the agreement of participating in this study. After gaining the agreement to participate in this study and the ethical approval by the Domestic Violence Service Centers as well as other contract out social service agencies, letters of introduction were distributed to these offices to recruit participants. Voluntary participants were encouraged to contact the researcher.

\section{Sampling Method and Characteristics of Participants}

Several participants voluntarily contacted the researcher and participated in this study. Purposive sampling and snowball sampling were then adopted to locate further participants with a minimum 3 years of working experience. In order to maximize the various experiences of participants to collect rich information, participants were 
selected whose work represented varied areas of domestic violence service. Sixteen female and one male domestic violence worker, aged 2560 years, were interviewed. The average of participants' working experience was 9 years.

\section{Data Gathering}

Data gathering involved the use of the long interview method (McCracken, 1988), an indepth interview process that enabled interviewers to explore participants' reflections on their experience as domestic violence workers. In-depth interviews lasting approximately 1.5$2 \mathrm{hr}$ were conducted in Chinese, in a safe and quiet office in the offices of domestic violence center of city government or in the offices of contract out social service agencies, between November 2006 and June 2007. An interview guide included questions such as "Tell me about your experiences of helping female domestic violence survivors." "What do you think about adopting feminist approach to help Taiwanese domestic violence survivors?" Field notes were prepared after each interview to assist the data analysis. The interviews were transcribed verbatim and were read and analyzed in Chinese in order to preserve the meaning of the dialogue. Only the quotes that appear in this article were translated into English.

\section{Data Analysis}

Line-by-line review of the transcripts was conducted and first-level codes (descriptors of important components of the interviews), including in vivo codes (using the participants' language), were noted in the margins (Charmaz, 2006; Glaser, 1978). The next step comprised constant comparison (Charmaz, 2006; Glaser \& Strauss, 1967) and refining and organizing the first-level codes into categories. Theoretical coding was undertaken to identify higher level codes and relationships among categories and to ensure saturation of categories (Charmaz, 2006), after which a central story emerged and was developed. The results correspond to the emergent categories. Findings were compared to the literature for further verification.

\section{Results}

The findings indicated that the Western approach to intimate partner violence practice is not fully applicable in Taiwan. The findings revealed discrepancies and gaps between Western approaches and Taiwanese culture and the consequent development of helping strategies that integrate cultural expectations related to Taiwanese women.

\section{A Therapeutic Focus on Equal Power Discouraged Battered Women from Seeking Professional Help}

Participants in this study reported that battered women still hold an image of the wife as being necessarily submissive to her husband. Therefore, feminist concepts of equality and equal power are not a focus of Taiwanese battered womens' concerns. In contrast, Taiwanese battered women are concerned about how they can transform their violent husbands' behaviors in order that they can return to being happy families. For example, one respondent reported

In my practice, there is an issue - I name it 'perfect family' issue. In this perfect family, the wife is tender, submissive, nurturing, and supportive to husband. If domestic violence happened and the wife was beaten by the husband in such a family, the battered wife's coping strategy is to transform the husband's behavior with tenderness and patience .... By looking at their (the violent husband and battered wife) interactions, it is so clear to me that the wife sacrifices herself so much 
in the relationship, however the wife interpreted her sacrifice as 'love', the idea of equality between husband and wife just does not occur to them (battered wives) .... It is difficult for social workers to discuss with battered women about equality ... battered women are concerned about how they can transform their husband's behaviors.

Another participant also described the difficulties of discussing issues of equality between husband and wife with battered women. This participant further described that seeking professional help, particularly seeking professional help for family issues, does not fit with Taiwanese traditional values. The consequence of discussing equality with Taiwanese battered women is to discourage them from seeking professional help.

I realized that many battered women carried traditional values, for example, don't reveal family conflicts to strangers, and wife should be submissive. They thought being referred to or seeking helps from Domestic Violence Center is kind of losing face ... on top of that, if you discussed about ideas (equality between husband and wife) which are very different from what they carried (ideology of submissive and obedient wife), they would avoid you (social workers), as a result, you would lose them.

One participant indicated that battered women often utilized a self-blaming perspective to analyze intimate partner violence particularly in the initial stage of seeking professional help. Therefore, working with battered women in their own context is of particular importance. This participant provided an example from her practice experience.

I had a client who suffered from long-term intimate partner violence, she did not seek professional help because she felt so ashamed to reveal her experience and blamed herself for intimate partner violence, so I reassured her that it was neither her fault nor a shame issue again and again, and this helped her continuously to work with me ... . My point is we (social workers) have to work with battered women in their own context rather than imposing them a different context (power between husband and wife).

Most participants in this study reported that the fight for women's equality is still stigmatized as the notion of "strong women" and violates female gender norms in Taiwanese social context. Consequently, a therapeutic focus of striving for equal power is not applicable and may scare battered women away from services.

\section{Self-Care Is Considered a Viable Approach for Working with Battered Women with Confucian Backgrounds}

Since discussion of equal power discourages Taiwanese battered women from seeking professional help, an approach that is different from the Western feminist approach is required to effectively build alliances with Taiwanese battered women. Particularly, discussions about self-care and the development of self-care plans for Taiwanese battered women are viable approaches that most participants in this study utilized. For example, one participant indicated "I had run a group for battered women for years, I modified the protocol based on the experiences of running these groups, and I realized that the workable goals of this Taiwanese battered women group should be focusing on helping battered women to see and treat themselves in a new perspective and self-care".

Another participant described a similar experience and considered self-care to be a manageable topic for Taiwanese battered women: "most battered women still hold onto traditional 
values, so don't ask them to move to a totally new topic (equality between husband and wife) that they are not able to manage. I adopt an innovative strategy, I discuss about self-care with battered women, it is manageable for them." In addition to self-care, other traditional values, particularly caring for children, are included in participants' strategies for assisting women to break the cycle of violence. One participant indicated that self-sacrifice and children are central to Taiwanese women. Therefore, this participant's approach is to tell battered women that engaging in self-care is demonstrating a good role model for their children. This strategy eventually helped battered women gain confidence, lead to self-determination.

Self-sacrifice and caring their children are predominant values, battered women are hesitant to take care of themselves because it is interpreted as selfish, so I would tell them that taking good care of yourself is to demonstrate a good role model to your children, and this strategy works well .... In my practice, when battered women know how to take good care of themselves, they became more confident about themselves, and that gives them power to make decisions.

\section{A Sound Intervention Plan Involves Balancing the Well-being of Battered Women and Their Children}

In addition to self-care, participants in this study also described that a sound intervention plan for battered women has to include the well-being of their children or even the wellbeing of other family members. An intervention plan that focused solely on battered women's well-being was not considered acceptable. One participant illustrated how a battered woman's decision was based on the well-being of her children.

Children are always the major concern of battered women ... if they are not able to take the children with them, they will go back to abusive relationships ... I was very impressed by one battered woman. She was placed in women's shelter by herself and did not have the children with her. She learned that she needed to collect evidence in order to successfully sue her abusive husband, get divorced, and get the custody of her children. So she went back to her abusive husband. She was prepared to collect evidence. It took her years to successfully attain a divorce and take her children away from her abusive husband ... I am not saying she is a good model, I am saying the plan of battered women always includes their children.

One participant explained that prioritizing the needs of children is central to the considerations of battered women across social economic backgrounds. "I worked with battered women with various social-economic statuses, no matter what their social-economic status is, the role of mother is always in the first priority, then the role of wife, she herself is always the least important ... the order of their various roles are central to their decision ...." Since the well-being of children is central to Taiwanese women, this participant's innovative helping strategy is to help battered women consider the impact of her situation in the abusive relationship on her children. "I often discussed with battered women that if you are sad and do not take care of yourself, what will the impact on your children will be?" This strategy motivated Taiwanese battered women to consider if they should stay in the abusive relationships and motivated them to make decisions.

\section{Discussion}

This study investigated the views of Taiwanese domestic violence workers regarding the applicability of Western feminist models of intervention in their work with battered women. The findings suggested that workers experienced 
discrepancies between the Western domestic violence practices in which they had been trained and their work with Taiwanese women whose beliefs and culture were embedded with Confucian ideology. This study also found that workers had developed alternative strategies that they believed to be useful in working with these women.

Participants in this study believed that a therapeutic focus on equal power between men and women discourages Taiwanese battered women from seeking professional help. They attributed this to the cultural socialization of women in Taiwan which is based on a Confucian ideology which emphasizes that wives should be subordinate and submissive to their husbands (Gallin, 1984; Lee, 1985; Tang \& Cheung, 1997). Influenced by these prescriptions, and the belief that submissive wives are loved and cherished by their husbands, the life scripts of many Taiwanese women are organized around this role. Given the emphasis of subordination and submissiveness, this study provided some insights into the reason that intervention practices focused on equal power between husband and wife may not be seen as viable.

In addition to the cultural regulation of submissiveness, another socialized belief identified by participants and confirmed in the literature is that battered women have the responsibility to transform their husbands' violent behaviors with patience and without disrupting the family unit (Lee, 1985; Lim, 1997). Consequently, consciousness-raising approaches which place the burden of violence on the perpetrator may not be accepted by victims and may further discourage help seeking.

The findings of this study also indicated that battered women hesitated to reveal family issues/secrets to domestic violence workers which are consistent with research findings, indicating that revealing family secrets to strangers is a taboo in Asian culture (Preisser, 1999; Tsang \& Sung, 2005). The culture norm of con- cealing abuse pervades women's experiences. Although the concept that domestic violence is not a matter solely to be dealt with in the private sphere came into practice through the enactment of the Domestic Violence and Sexual Assault Act in 1998 (Domestic Violence and Sexual Assault Prevention Committee, Ministry of Interior, 2007), this is a very recent change that has not received widespread cultural acceptance.

An emphasis on women's self-care was identified by participants as an innovative approach which could incorporate Taiwanese cultural premises. Self-sacrifice is considered to be a woman's virtue (Gallin, 1984; Lee, 1985). Since this premise is strongly conveyed in cultures with Confucian backgrounds, moving from a requirement for self-sacrifice and toward a notion of self-care could be seen as more acceptable in that it moves along a continuum of a woman's virtue. This was juxtaposed by participants with the empowerment approach which is common to the Western feminist model of intervention, which was seen as too far removed from the women's virtue continuum. Leaving one's husband, divorce, or equal power between husband and wife is stigmatized in this culture. Advocating for such a tremendous disjuncture is believed to discourage Taiwanese battered women from help seeking and instituting changes in their lives. Although identifying abusive situations, analyzing the situations in power-control perspective, and developing safety plans are still important procedures in helping battered women, this finding suggests that understanding cultural premises and incorporating this understanding in approaching battered women with specific cultural background is important. In particular, a self-care plan is workable alternative construction in the context emphasizing self-sacrifice.

The participants in this study believed that a sound intervention plan for battered women must include the well-being of both the battered women and their children. This is consistent 
with the Confucian ideology which demands that mothering roles are to be a woman's first priority (Xiong, 1998). Taiwanese culture continues to be family-oriented, and consequently, individualism and fighting for rights are considered to be selfish and self-centered. Such behaviors are not viewed as appropriate or acceptable for women. In contrast, the prescribed women's roles regulate women to put family members' interests first, particularly the interests of their children (Xiong, 1998). Therefore, what is considered to be a good decision for a woman embedded in Confucian culture is a decision in which the family's well-being is the primary consideration (Preisser, 1999; Tsang \& Sung, 2005; Yoshihama, 2005). Participants in this study indicate that the battered women with whom they work have modified this concept somewhat and believe their children are central to their consideration of well-being. This provides an opening for intervention by focusing on the best interest of the child.

\section{Conclusions and Implications}

The findings of this study lead to the conclusion that inclusion of battered women's cultural beliefs and culturally prescribed role expectations are essential components of social work practice with victims of intimate partner violence. The findings not only supported the notion that cultural variations should be included in sound intimate partner violence practice but also revealed particular strategies that are effective in helping battered women in Taiwan or battered women with Confucian backgrounds. Therefore, this study supports previous research findings that suggest that practitioners must blend diverse cultural beliefs and practices into intimate partner violence service provision in order to avoid victim-blaming attitudes. Cultural knowledge is important for social workers working with battered women with diverse cultural backgrounds in approaching, building working alliance with them, and in assisting with instituting change throughout the helping process.

Several helping strategies are suggested in this study for working with battered women with Confucian background in order that they can feel justified in accessing and utilizing services. Discussing self-care plan with battered women instead of emphasizing equal power between husband and wife is viable. Discussing the impact on their children may motivate battered women to further consider other options. Encouraging battered women to develop coping strategies consistent with cultural requirements may be more comfortable for battered women with Confucian background.

The definition and scope of women's well-being vary across cultures, particularly, it varies between individualistic cultures and collectivist cultures. This culturally ascribed concept of women's well-being influences the decision-making processes of battered women. Therefore, battered women's decision-making process should be understood and discussed in the context of culturally defined women's well-being rather than imposing certain ideology of well-being.

Intimate partner violence occurs in many cultures; however, helping strategies with diverse women of cultures are still woefully missing. It is necessary to determine strategies employed by intimate partner violence practitioners in working with battered women from diverse cultural backgrounds. Therefore, efforts to explore culturally sensitive intimate partner violence models should continue in order to best serve the needs of battered women with diverse cultural backgrounds.

\section{Funding}

National Science Council, Taiwan (Project No. NSC 95-2412-H-029-009). 


\section{Acknowledgments}

The authors wish to thank National Science Council, Taiwan, for their generous sponsor. Conflict of Interest: None declared.

\section{References}

Almeida, R. V., \& Doland-Delvecchio, K. (1999). Addressing culture in batterers intervention. The Asian Indian community as an illustrative example. Violence Against Women, 5, 654-683.

Charmaz, K. (2006). Constructing grounded theory. A practical guide through qualitative analysis. Thousand Oaks, CA: Sage Publication.

Chen, S. (2003). The process of mate selection, experiencing abused, and help-seeking of spouses from Mainland China. Community Development Quarterly, 101, 182-199. (in Chinese).

Collins, P. (1990). Black feminist thought: Knowledge, consciousness, and the politics of empowerment. Boston: Unwin Hyman.

Cousineau, M.-M., \& Rondeau, G. (2004). 'Toward a transnational and cross-cultural analysis of family violence'. Violence Against Women, 10, 935-949.

Crichton-Hill, Y. (2001). Challenging ethnocentric explanations of domestic violence. Let us decide, then value our decisions-A Samoan response. Trauma, Violence, \& Abuse, 2, 204-214.

Danis, F. S. (2003). Social work response to domestic violence: Encouraging news from a new look. Affilia, 18, 177-191.

Davis, A. (1981). Women, race and class. London: Women's Press.

Domestic Violence and Sexual Assault Prevention Committee, Ministry of Interior (2008). Introduction to the Committee. Retrieved on July 7, 2008, from http://dspc.moi.gov.tw/ct.asp? $\mathrm{xItem}=1380 \& \mathrm{CtNode}=602 \& \mathrm{mp}=5$.

Dominelli, I. (2002). Feminist social work practice theory and practice. New York: Palgrave.

Evan, K. M., Kincade, E. A., Marbley, A. F., \& Seem, S. R. (2005). Feminism and feminist therapy: Lessons from the past and hopes for the future. Journal of Counseling and Development, 83, 269-277.

Gallin, R. S. (1984). The entry of Chinese women into the rural labor force: a case study from Taiwan.
Signs: Journal of Women in Culture and society, 9, 383-398.

Glaser, B. G. (1978). Theoretical sensitivity: Advances in the methodology of grounded theory. Mill Valley, CA: Sociology Press.

Glaser, B. G., \& Strauss, A. L. (1967). The discovery of grounded theory: Strategies for qualitative research. New York: Aldube de Gruyter.

Hooks, B. (1981). Ain't I a woman. Black women and feminism. London: Pluto Press.

Hudson-Weems, C. (2001). Africana womanism: The flip side of a coin. The Western Journal of Black Studies, 25, 137-145.

Jaimes-Guerrero, M. A. (2003). Patriarchal colonialism and indigenism: Implications for native feminist spirituality and native womanism. Hypatia, 18, 58-69.

Lee, M. C. (1985). On gender and gender role. Indigenous Psychological Research in Chinese Societies, 6, 260-299. (in Chinese).

Lim, In-Sook (1997). Korean immigrant women's challenge to gender inequality at home: The interplay of economic resources, gender, and family. Gender and Society, 11, 31-51.

McCracken, G. (1988). The long interview. Thousand Oaks, CA: Sage Publications.

Preisser, A. B. (1999). Domestic violence in South Asian communities in America. Violence Against Women, 5, 684-699.

Tang, C., \& Cheung, F. (1997). Effects of gender and profession type on definitions of violence against women in Hong Kong. Sex Roles, 36, 837-849.

Tang, C., Wong, D., \& Cheung, F. (2002). Social construction of women as legitimate victims of violence in Chinese societie. Violence Against Women, 8, 968-996.

Tsang, A. Y., \& Sung, P. (2005). The social construction of concealment among Chinese women in abusive marriages in Hong Kong. Affilia, 20, 284-299.

Xiong, Xian-Guan (1998). Women's status in the Confucian paradigm. Journal of Philosophy, 24, 100-117. (in Chinese).

Yoshihama, M. (2005). A web in the patriarchal clan system. Tactics of intimate partners in the Japanese sociocultural context. Violence Against Women, 11, 1236-1262. 